\title{
AIDS, ECONOMIC GROWTH AND INCOME DISTRIBUTION IN SOUTH AFRICA
}

\author{
NiCOLI NATTRASS $* 1$
}

SOUth AFrica IS HOME TO MORE HIV-POSITIVE PEOPLE than any other country in the world. This is a developmental disaster, yet our understanding of the economic impact of the AIDS pandemic is sketchy at best. Macroeconomic modellers are divided over whether the overall impact of the epidemic will be to raise or lower per capita GDP, and there are no studies of the impact of AIDS on income distribution.

This paper provides a critical overview of recent macroeconomic research on the impact of AIDS in South Africa. It is not a comprehensive bibliographic review (as in CADRE 2000a and 2000b), but rather a selective analysis of recent and important pieces of economic research. The key objective is to explain, in an accessible manner, how different macroeconomic models arrive at different results and to point to the limitations of these models in particular, their failure to take into account the dynamic adjustments suggested by firm-level studies.

It is argued that the recent sharp decline in the cost of antiretroviral medication will probably result in more firms providing such medication to their workers (particularly skilled workers). If so, then the economic impact of AIDS will be less substantial than that projected by the main macroeconomic models. However, the distributional implications are unsettling.

1 School of Economics, University of Cape Town. 


\section{THE DEMOGRAPHICS}

South Africa's leading demographic models (ASSA2000 ${ }^{2}$ and Metropolitan ${ }^{3}$ ) are calibrated to reproduce the age, race and gender profile of HIV infection as indicated by the government's antenatal clinic survey. Both models predict that the South African population will grow by a mere 1.5 million between 2000 and 2015 (i.e. 10 million fewer than would have been the case in a no-AIDS scenario) and that the labour force will remain almost stagnant over the next fourteen years. ASSA2000 predicts that HIV prevalence will grow from its current level of 11 per cent, and will peak at 16.2 per cent in 2006 (i.e. 7.7 million people). The number of people with full-blown AIDS is predicted to rise five-fold to 880,000 in 2005, and then to 1.2 million people in 2015 .

A recent national survey concluded that there are no significant differences in HIV-prevalence between the employed and the unemployed (Shisana and Simbayi, 2002:53). There are, however, serious problems of bias regarding the HIV prevalence data in this survey, and the available data analysis is of poor quality. ${ }^{4}$ Most demographic modelling indicates that HIV prevalence rates are 30-50 per cent higher amongst the unemployed, largely because of the large share of young and female people (BER, 2000:7).

HIV prevalence appears to vary between skill levels. Drawing on insurance data and other private sector information, Dorrington (2001) reports that those in the higher job grades have

2 The ASSA2000 model was developed by the Actuarial Society of South Africa It is available on the Actuarial Society website: www.assa.org.za/aidsmodel.asp.

3 This model was developed by Peter Doyle and is propriety to Metropolitan Life (a large insurer in South Africa).

4 Survey non-response was particularly high for whites, and for people living in rural areas and informal settlements. The data set has not been publicly released. This is shocking given the urgent need for AIDS related information, and given the inadequate data analysis in the only available report (Shisana and Simbayi (2001)). 
an HIV prevalence of only 2.5 per cent to 3 per cent. ${ }^{5}$ This information was used in the ASSA2000 model to fit the epidemic curves for white and Asian people (who tend to be concentrated in the higher job grades) rather than the antenatal survey data (which is unreliable for higher income groups). The ASSA2000 model predicts that HIV prevalence will peak at 3.2 per cent (2011) for whites, at 4.8 per cent (2010) for Asians, at 6 per cent (2010) for 'coloureds' (i.e. mixed race) and at 19.5 per cent (2006) for Africans.

One of the problems with the demographic models for economic analysis is the difficulty involved in teasing out the impact of race from other variables such as skills and income. As noted above, the ASSA2000 model used information on HIV prevalence by skill to project epidemic curves for whites and Asians. However, for Africans and coloureds, researchers have had to move from information about race to assumptions about skill prevalence. The Metropolitan and ING-Barings macroeconomic models (discussed below) derive HIV skills profiles by 'overlaying' the 1996 census data on occupation with age, gender and racial HIV profiles per province (see ING-Barings, 2000:7). This results in a far higher estimate for HIV prevalence amongst skilled workers in 2000 (7.2 per cent for highly-skilled workers, to 12.1 per cent for skilled workers and 14.3 per cent for unskilled workers) than is assumed in the ASSA2000 model.

These highly varying estimates of prevalence by skill level are a problem for macroeconomic modellers because of the profound impact of skills shortages on economic growth. As can be seen in

5 This is supported to some extent by national survey data, which found that HIV-prevalence was lower for those with tertiary education (Shisana and Simbayi, 2002:54). However, these results need to be treated with caution (see footnote 3).

6 The recent national survey estimated white HIV prevalence to be much higher, i.e. 6.2 per cent (Shisana and Simbayi, 2002:46). However, given the problems of bias and the fact that the 95 per cent confidence interval for this estimate is 3.1-9.2 per cent, one should not conclude that this higher estimate of white HIV prevalence is necessarily superior to estimates derived from other data sources. 
Table 1, unemployment amongst the highly skilled is already very low. According to an ILO study, more than 60 per cent of firms in 2000 reported that they would have problems replacing skilled labour (2000:5). The point at which the economy 'runs out' of skilled labour has major implications for the projected macroeconomic impact of AIDS. According to the Metropolitan model, 1.4 per cent of highly skilled workers will have full-blown AIDS by 2005, this estimate rising to 3.5 per cent in 2015 (Abt/Metropolitan, 2000). Given that less than 1 per cent of the highly skilled are unemployed, there will not be nearly enough people to replace those dying of AIDS in these categories. Therefore, unless firms react by providing their skilled workers with life-prolonging antiretroviral medication, the economy will be constrained by skills shortages and skilled wage pressure (as described in BER, 2001). This constraint will kick in later if the ASSA2000 estimates are closer to the mark.

Table 1. The Structure of South Africa's Labour Force (1996 Census Data)

\begin{tabular}{|c|c|c|c|c|c|c|}
\hline \multirow[b]{2}{*}{ Economically active } & \multicolumn{2}{|c|}{ Highly Skilled*** } & \multicolumn{2}{|c|}{ Skilled** } & \multicolumn{2}{|c|}{ Semi \& Unskilled* } \\
\hline & Number & percentage & Number & percentage & Number & percentage \\
\hline Formally employed & $1,300,009$ & 92.1 & $2,899,334$ & 76.5 & $3,509,890$ & 40.9 \\
\hline Informally employed & 100,177 & 7.1 & 289,901 & 7.7 & 710,223 & 8.3 \\
\hline Unemployed & 11,148 & 0.8 & 598,083 & 15.8 & $4,366,238$ & 50.8 \\
\hline Total labour force & $1,411,334$ & 100 & $3,787,318$ & 100 & $8,586,351$ & 100 \\
\hline $\begin{array}{l}\text { Composition } \\
\text { (percentage) }\end{array}$ & \multicolumn{2}{|c|}{$10.2 \%$} & \multicolumn{2}{|c|}{$27.5 \%$} & \multicolumn{2}{|c|}{$62.3 \%$} \\
\hline HIV prevalence in & \multirow{2}{*}{\multicolumn{2}{|c|}{$\begin{array}{c}13.3 \% \\
(18.3 \%)\end{array}$}} & \multirow{2}{*}{\multicolumn{2}{|c|}{$\begin{array}{c}20.2 \% \\
(25.4 \%)\end{array}$}} & \multirow{2}{*}{\multicolumn{2}{|c|}{$\begin{array}{c}22.8 \% \\
(27.6 \% \mathrm{t})\end{array}$}} \\
\hline 2005 (2015)\# & & & & & & \\
\hline AIDS prevalence in & \multicolumn{2}{|c|}{$1.4 \%$} & \multicolumn{2}{|c|}{$1.9 \%$} & \multirow{2}{*}{\multicolumn{2}{|c|}{$\begin{array}{c}2.2 \% \\
(4.7 \%)\end{array}$}} \\
\hline 2005 (2015)\# & \multicolumn{2}{|c|}{$(3.5 \%)$} & \multicolumn{2}{|c|}{$(4.2 \%)$} & & \\
\hline
\end{tabular}

***Highly-skilled (professional, semi-professional and technical occupations, managerial, administrative and executive occupations).

** Skilled (clerical services and sales occupations, farmers, farm managers, artisans, apprentices and related occupations, production foreman, production advisor).

* Semi- and unskilled (all occupations not defined as highly-skilled or skilled).

\# Data from Abt/Metropolitan

Source: BER, 2001: 11, 12.

The close association between unemployment and poverty in South Africa has been well established (Leibbrandt et al, 2000, Seekings, 2000). Household survey data indicates that AIDS- 
affected households are in a particularly vulnerable position as they have higher rates of unemployment and are more dependent on non-employment income like pensions (Booysen et al, 2001b; Steinberg et al, 2002). This suggests that one or more of the following is the case: people living in households with limited (if any) access to wage employment are more vulnerable to HIV/AIDS infection; that AIDS-affected households have experienced disproportional employment losses because of AIDS; and that people living with AIDS migrate to households with pensioners in order to be taken care of.

What does this mean for overall inequality? All else being equal, households which lose a breadwinner through AIDS will fall further down the income distribution scale. If the job is taken by a previously unemployed person, then that person's household will move up the income distribution scale. The overall Gini coefficient will thus remain broadly unchanged. However, if firms react by cutting back on the number of jobs, then the number of households without access to a breadwinner will rise, thus worsening the Gini coefficient. If average wages rise at the same time (perhaps in response to increased pressure from workers to compensate them for the burden of higher medical insurance and health expenditure, or perhaps because the average worker is becoming more skilled as firms get rid of unskilled workers first) then inequality will worsen further.

At this point the importance of economic modelling becomes clear. Questions like 'what is the likely impact of AIDS on labour demand and income' need to be answered before anything can be said about the impact of AIDS on income distribution. But the issue goes beyond the partial equilibrium impact of labour demand and wages. We need to know how the impact of AIDS on firms (and the government) feeds through the broader economy to impact on the level of national income.

Any discussion of the impact of AIDS on distribution requires information about the size of the pie (the GDP) and the number of people in need of a slice (the population). AIDS slows income growth - but it also slows population growth. If the population 
falls faster than income, then per capita income will rise. But while this is theoretically possible, it is not common. Econometric research indicates that AIDS has either had an insignificant impact on the growth of per capita income in developing countries (Bloom and Mahal, 1997) or has reduced it (Bonnel, 2000). ${ }^{7}$ Bonnel's results indicate that in the case of a typical sub-Saharan country with a prevalence rate of 20 per cent', the growth rate of per capita income would be reduced by 1.2 percentage points a year because of AIDS (2000:846). But whether absolute per capita income is higher or lower as a result of AIDS in any particular country is ultimately an empirical question.

As discussed below, two of the three South African models predict a rise in per capita income, whereas the third predicts a fall. ${ }^{8}$ Whether per capita income rises or falls has disturbing ethical and policy implications. The Malthusian possibility that AIDS may increase per capita income might suggest to those policy-makers with no respect for human life that AIDS may be in some sense 'welfare-enhancing'. They may conclude that it is economically rational to do little to prevent the AIDS epidemic from taking its course. Leaving aside the moral and ethical problems of such a position, it does point, at minimum, to the importance of producing the best possible macroeconomic modelling work and showing how different assumptions and theoretical underpinnings produce different results.

\section{MODELLING THE MACROECONOMIC IMPACT OF AIDS}

The earliest attempts to model the economic impact of AIDS in South Africa were those of Broomberg et al (1991) and Trotter

\footnotetext{
7 See summary of international econometric studies of the economic impact of AIDS in Barnett and Whiteside (2002:286-7). Most studies show a decline in per capita income as a result of the AIDS pandemic.

8 Abt Associates (2000:49-50) also conclude that AIDS is likely to increase per capita incomes - although they do so not on the basis of their own macroeconomic model, but rather by reviewing modelling work from the rest of Africa and modifying it to take into account factors specific to South Africa (such as high unemployment).
} 
(1993). They adopted a 'human capital' approach that summed up both the expected direct costs of AIDS (i.e. health costs) as well as indirect costs (discounted lost future earnings) over time. However, such approaches do not consider the full macroeconomic ramifications of these costs on the rate and pattern of economic growth.

Macroeconomic modelling typically entails a three-step process. First, modellers use an existing macroeconomic model to project what growth would look like in the absence of AIDS. Then they hypothesize a set of presumed 'channels' through which the epidemic is assumed to affect the broader economy. Finally, they estimate (and guesstimate) the size of these various channel effects, plug the assumption into the model and see what growth path results. This 'growth with AIDS' scenario is then contrasted with the 'growth without AIDS' scenario.

A major limitation of this approach is, of course, the assumption that the current growth path is the 'growth in the absence of AIDS'. While this was a reasonable assumption for models in the late 1980s and even early 1990s, it is becoming increasingly problematic. As McPherson et al, put it, the impact of AIDS cannot

"be treated as an 'exogenous' influence that can be 'tacked on' to models derived on the presumption that the workforce is HIV-free. HIV/AIDS has become an 'endogenous' influence on most African countries that has adversely affected their potential for growth and development" (2000:3).

This is particularly the case with regards South Africa. Employment has fallen so sharply over the past decade that Fedderke and Mariotti (2002) argue that a 'structural break' took place in 1990. While a range of factors (including labour market regulation and globalisation) contributed to this, it is also very likely that firms have been reacting to the presence, and threat, of AIDS in the workforce by shedding jobs - particularly amongst the unskilled.' If the impact of AIDS is already being felt in the 'noAIDS' scenarios, then either the impact of AIDS will be under-

$9 \quad$ See article in The Economist, $8^{\text {th }}$ February, 2001. 
estimated in the subsequent comparative analysis, and/or the modelling of economic dynamics will be compromised.

It is also worth emphasising that the estimated economic impact depends in large part on the nature and design of the macroeconomic model being used. The first big modelling exercise (ING-Barings, 2000) used time series information together with a social accounting matrix (SAM) that provided more detailed household-level data. Arndt and Lewis (2000) made use of the same SAM, but in the context of a more neoclassical computaable general equilibrium (CGE) model. The most recent macroeconomic modelling exercise (that of the Bureau for Economic Research (BER, 2001) at Stellenbosch University) does not use a SAM, but instead builds on their Keynesian framework using insights from available research, including that by INGBarings.

There are many 'channels' through which the AIDS pandemic can affect the broader economy. AIDS has an immediate (or 'first order') impact on the size (and efficiency) of the labour force. But while demographic models can provide a broad indication of the impact of AIDS on the size of the labour force, the impact on the efficiency of the labour force is much harder to estimate. As noted above, there is very little reliable data on the distribution of HIV prevalence across skill bands - or between the employed and unemployed.

The other first-order impact of AIDS is on patterns of consumption (i.e. it is typically assumed that more household resources will be allocated to health care $\left.{ }^{10}\right)$. Although there is an emerging body of household-level research (e.g. Booysen et al 2001; Booysen, 2002; Johnson et al, 2002), there is as yet no information

\footnotetext{
10 According to a recent survey of AIDS affected households in South Africa, 34 per cent of household income is spent on health care by AIDSaffected households. This is dramatically higher than the national average (4 per cent) (Johnson et al, 2002). This data is consistent with a study from Tanzania that which found that people with AIDS had higher medical expenditure (and were more likely to seek medical assistance) than those with other terminal illnesses (cited in Desmond et al, 2000:42).
} 
that can be generalized to the national level. Methodological problems concerning the drawing of samples and the definition of AIDS-affected households makes it difficult to compare the results of (and generalise from) the existing studies of the economic impact of AIDS on households (Dike, 2002).

Studies from South Africa and other developing countries are suggestive, but often contradictory. For example, there is research showing that households may erode savings by paying for the health costs of AIDS sufferers - or they may increase savings in order to support surviving household members (see Ainsworth \& Over, 1994; and CADRE, 2000a). Given that HIV infection is concentrated amongst poorer South Africans, it is unlikely that savings will increase as a result of AIDS. Booysen et al (2001) found that AIDS-affected households draw on available savings to finance medical costs and funerals, but Samson (2002) ${ }^{11}$ found an indeterminate impact of AIDS on household savings. Oni et al (2002) concluded that AIDS-affected households had lower levels of savings and higher levels of borrowing from relatives than non AIDS-affected households. According to Booysen (2002), AIDSaffected households in QwaQwa borrowed money from friends and relatives, whereas those in Welkom were more likely to borrow from micro-lenders. Higher borrowing from relatives probably translates into lower levels of savings by these relatives, and borrowing from micro-lenders almost certainly results in AIDS-affected households being caught in a debt-trap. In short, studies of savings behaviour remain limited to isolated household studies and there is as yet no reliable estimate of the overall impact of AIDS on total household savings.

Research in Africa indicates that AIDS-affected households shift spending away from durable goods and towards nondurables (ILO, 2000:5-7; Abt Associates, 2000:52). This does not,

\footnotetext{
11 They found that livestock ownership was an important source of savings, and that livestock sales were used to finance education and funerals. However, they found that households reporting AIDS symptoms were less likely than other households to have sold livestock in the previous year (2002:1165).
} 
however, mean that the overall pattern of demand will change in this direction. Firstly, AIDS-affected households could spend relatively less on durables and absolutely less on non-durables like food (as was the case in the Booysen et al (2001) study). In such a scenario, the demand for both durables and non-durables will fall.

Secondly, the overall impact on the pattern of consumption is mediated by the distribution of AIDS-affected households across the income distribution (and by differential consumption patterns across income brackets). For example, the ING-Barings model assumes that AIDS will result in a greater share of income going to richer households (as skilled wages rise in response to skilled labour shortages). Data in the SAM used by ING-Barings indicates that richer households spend more on services and durable goods than do poorer households. Thus as skilled workers rise up the income distribution scale, the model predicts that this will cushion the impact of lower demand for durable goods from AIDSaffected households. ${ }^{12}$ The ING-Barings model uses demographic data on the expected size of the labour force and then 'weights' it to account for skill composition (i.e. skilled labour carries a higher weight) and adjusts it downwards to account for loss of productivity as a result of AIDS. ${ }^{13}$ This has been criticized by CADRE (2000b:14) on the grounds that it probably underestimates the contribution to productivity of experienced workers in lowerskill categories (and hence underestimates the costs of replacing such workers) and underestimates the potential for high-skill capacity bottlenecks in some sectors.

AIDS also affects people indirectly - i.e. through the impact of 'second-order' effects that occur after firms and the government

12 CADRE argues that this is 'at odds with research elsewhere which suggests that households cut back on durable consumption to maintain food intake' (2000b:14). In this regard, however, CADRE misses the point that the overall impact on demand is a function not only of changes in expenditure patterns at the level of the individual household, but also a function of the allocation of income between households.

13 ING-Barings assumes that 'for every person with full-blown AIDS, four months of person year equivalent labour supply will be lost' (2000:11). 
have responded to the first-order impact of AIDS. These impacts are even more difficult to estimate. Does one assume that firms will respond to higher medical costs for employees and lower productivity by replacing labour with machinery - and if so, by how much and in which sectors? Will firms respond to higher (direct and indirect) labour costs by raising prices (i.e. passing costs on to consumers) or reducing profits (thereby probably reducing investment in subsequent periods)? To what extent will they share the costs with workers by constraining wage growth, thereby lowering consumer demand and growth in subsequent periods? The different models assume different scenarios, and model the way in which the assumptions impact on economic growth in different ways. ${ }^{14}$

There are similar problems regarding the reaction of government to the AIDS pandemic. Will government increase spending on health - and if so, will this be at the cost of lower spending on other items; and if so, which? Whether cuts are made to military or education expenditure has very different implications for long-run growth. Alternatively, one could assume that the government responds by increasing borrowing or taxation to finance the increase in health spending. Depending on the nature of the macroeconomic model, such increases have further knock-on effects. In more Keynesian models (like ING-Barings and BER) deficit-financed health spending increases demand and growth, whereas in the CGE model of Arndt and Lewis, increased borrowing reduces private investment and hence constrains growth over time.

14 Employers shoulder two-thirds of the higher medical cost burden in the ING-Barings model, and half in the BER model. Both assume that half of this burden is subsequently passed onto consumers. As regards indirect effects (i.e. lower productivity, increased turnover, recruitment costs etc.) the BER model assumes that productivity of infected workers is reduced by 40 per cent (thus lowering the effective labour supply) and that this burden is shared between firms and consumers (BER, 2000:23). ING-Barings assumes no such additional reduction in the effective labour supply - hence the differences in projected trends for the labour force growth in the models (see Table 2). 
Both the ING-Barings and BER models predict a slight worsening of the ratio of budget deficit to GDP as government faces the dual pressure of depressed tax revenues and increased demand for spending on health. They assume that the government will continue on the path of fiscal discipline and not engage in excessive borrowing or inflationary forms of financing the deficit. However the BER model assumes greater wage pressure as a result of AIDS (driven primarily by skilled-labour shortages) and assumes that the Reserve Bank responds to such inflationary forces by pushing up interest rates.

Table 2. Percentage Point Differences between the AIDS and No-AIDS Scenarios in the ING-Barings (2000) and Bureau for Economic Research (2001) Macroeconomic Models

\begin{tabular}{lll}
\hline & ING-Barings (2000) & BER (2001) \\
Impact of AIDS on: & $\mathbf{2 0 0 2 - 2 0 1 5}$ & $\mathbf{2 0 0 2 - 2 0 1 5}$ \\
Real GDP growth p.a. & -0.6 & -0.5 \\
Real Gross Domestic Fixed Investment growth p.a. & 0.0 & -1.2 \\
Real Private Consumption growth p.a. & -0.7 & -0.3 \\
Total population growth p.a.** & -1.5 & -1.3 \\
Total labour force growth p.a.*** & -1.2 & -1.6 \\
Employment growth p.a.**** & -0.6 & -0.6 \\
Growth in the unemployment rate (i.e. per cent of labour & -0.9 & -2.0 \\
force without formal jobs)* & 0.9 & 0.9 \\
Real per capita GDP growth p.a.\# & 0.6 & 2.9 \\
Interest rate (per cent point difference in the level) & 0.7 & 0.2 \\
Budget Deficit/GDP (per cent point difference in the level) & 0.7 & \\
\hline
\end{tabular}

* $\quad$ Figures for BER estimated from level data in (2001:38).

** Figures for ING-Barings calculated from data in (2000:6).

*** Figures for ING-Barings calculated from data in (2000:10).

NB data for ING-Barings is a labour force figure weighted by skill-level.

**** Employment figure for ING-Barings estimated from data in (2000:2).

\# Figures for ING-Barings calculated from data in the Table.

Despite these differences, the ING-Barings and BER models arrive at broadly similar findings with regard to GDP and employment (see Table 2). They both estimate that AIDS will reduce the growth rate of GDP by 0.6 percentage points per annum. As AIDS is assumed to reduce population growth by more than it reduces GDP growth, both models predict an increase in per capita income (of just under 1 percentage point per annum). A similar logic 
underpins the prediction in both models that the rate of unemployment will fall as a result of the AIDS pandemic (employment falls, but because the labour force falls faster, the proportion of those without work decreases relative to that which would have occurred in a no-AIDS scenario).

Despite similarities in the overall growth impact, the BER and ING-Barings models tell different stories as to why growth is constrained by AIDS. Whereas the ING-Barings model assumes that lower labour supply and lower labour productivity will induce firms to invest in capital (thus preventing investment demand from falling in the aggregate), ${ }^{15}$ the BER model assumes that investment will be limited by shortages of skilled workers (needed to operate the capital equipment) and by reduced profitability. ING-Barings tells the story of a 'vicious cycle' in which reduced household income translates into lower consumption spending which translates into lower demand and hence lower growth and household income.

By contrast, the BER model assumes that there will be a strong upward pressure on skilled wages (as skills shortages intensify and as workers resist the erosion of their take-home pay due to rising costs of medical insurance). The BER modellers assume that the increase in wages will exceed any decrease in employment - and thus that wage increases will boost household income in the aggregate (although by implication it will be more concentrated in the hands of those households which still have employed members). Neither model provides an explicit projection for income distribution, although both predict that the share of income going to higher-income households will rise over time (ING-Barings, 2000:14; BER, 2001:31-2). But at the same time, the models predict that average living standards (i.e. per capita income) will rise relative to a no-AIDS scenario and that one of

\footnotetext{
15 CADRE has criticized this aspect of the ING-Barings model, describing the induced investment response as 'mechanistic' and failing to take into account the possibility that lower growth will undermine investor confidence and hence will reduce investment (2000b:15-16).
} 
the central determinants of poverty, unemployment, will fall.

The macroeconomic model of Arndt and Lewis (2000) contains different assumptions and arrives at different conclusions. Arndt and Lewis assume a far greater negative impact on productivity and investment, and a far greater impact on government spending and interest rates. ${ }^{16}$ Largely as a result of this, they project a much greater impact on GDP growth - i.e. growth is reduced by an average of about two percentage points a year between 2002 and 2010. They attribute almost half (45 per cent) the blame for this to the increase in the government deficit (which in their model 'crowds out' private investment) and about a third (34 per cent) of the blame to the negative impact of AIDS on total factor productivity growth (2000:879-881).

This drop in growth is sufficiently large to exceed the drop in population - and hence per capita income in their model is projected to fall. They conclude that per capita income in 2010 will be 8 per cent lower than it would otherwise have been in the absence of the AIDS pandemic (2000:877). Arndt and Lewis show that if government-related AIDS expenditures and private expenditure on health and food are excluded, then per capita incomes decline by 13 per cent (relative to the no-AIDS scenario). They thus conclude that 'the survivors of the AIDS epidemic are left with a smaller economic "pie" and more of this pie is directed towards non-discretionary health and food expenditures' (2000: 877).

Also, unlike the BER and ING-Barings models, Arndt and Lewis predict that the unemployment rate amongst semi-skilled and unskilled workers will rise and that the overall unemployment rate will remain broadly constant. They argue that 'while the unskilled labour pool is smaller, slower growth means that the demand for labour is correspondingly lower. These two effects

\footnotetext{
16 Arndt and Lewis assume that total factor productivity growth is reduced to one half of that in the no-AIDS scenario at the height of the epidemic. This is an attempt to capture more fully the harmful economic impact of hiring, training, absenteeism, work-force disruption, slower technological adaptation etc (2000:872-4).
} 
offset one another leaving the unemployment rate essentially unchanged' (2000:879).

So where does this leave our understanding about the macroeconomic impact of AIDS? In a rather confused state, to say the least. The ING-Barings and BER models come to similar conclusions about the likely impact on growth, unemployment and per capita income - but they do so via different economic channels. The Arndt and Lewis model not only highlights a different set of economic dynamics, but concludes that the impact on growth will be more significant and that the final impact of AIDS on per capita income will be negative.

A large part of the explanation for these differences lies in the different theoretical underpinnings of the macroeconomic models. Macroeconomic modelling entails imposing a theoretical framework on a set of economic data, and then using the model to project forward in time (or to simulate the impact of economic shocks). The key point is that very different theoretical models assuming different relations between economic variables can all generate a good 'fit' with the current (and historical) data, but produce very different predictions and results from simulations.

In the case of the three macroeconomic models discussed here, a key difference pertains to the way in which they model the economic impact of higher government expenditure. As discussed above, the Arndt and Lewis model assumes that government borrowing crowds out private investment and lower growth over the longer term. In the more Keynesian models of ING-Barings and the BER, the increase in government spending is assumed to support growth by keeping consumption buoyant. ING-Barings in fact argues that if the government maintains strict fiscal discipline in the face of the AIDS pandemic (i.e. does not allow the deficit to rise as a proportion of the GDP) then this would serve to drain demand even faster out of the economy, thus dragging down GDP (and government revenues) in a 'downward spiral' (2000:22). The Arndt and Lewis model, by contrast, assumes that such a downward spiral would not happen because private investment would increase. 
Such differences have major implications for government policy. One theoretical approach implies that borrowing in order to finance increased health expenditure supports growth, the other implies the reverse. And in the absence of any clear way of evaluating the different models, policymakers are left in a state of befuddlement over how to respond at the fiscal level. ${ }^{17}$

But differences between the models also arise as a result of the lack of adequate information about key behavioural coefficients in the models: how much will total factor productivity fall and to what extent will the available pool of labour become less effective? How will households realign their spending priorities in the face of AIDS? How much more expensive will labour become for firms? To what extent will they be able to pass on the higher costs in the form of price increases? And will investment rise in response to incentives to become more capitalintensive, or will investors take their money out of the country? Any macroeconomic modelling exercise has to make judgments about all of these choices - and in each case, the estimate could be wildly off track. As Over (1992) showed ten years ago, modelling the macroeconomic impact of AIDS in Southern Africa is highly sensitive to assumptions about the prevalence of HIV across skill bands and the proportion of health expenditure that is financed out of savings. This remains true today. One must thus be very cautious about all macroeconomic models estimating the impact of AIDS. At best, they help us think through the dynamic economic impact of AIDS. At worst, they are a misleading and shaky house of cards.

\section{THE IMPACT OF AIDS ON FIRMS}

One of the weaknesses with the macroeconomic modelling work discussed above is that it operates with a very limited understanding of the way that firms are likely to respond to AIDS. International research on the impact of AIDS on firms tends to

\footnotetext{
17 See also Barnett and Whiteside (2002:290-92) for commentary on the different policy implications of different modelling exercises.
} 
draw a distinction between direct and indirect costs. ${ }^{18}$ Direct (or 'out-of-pocket') costs include pension and provident fund contributions, service bonuses, absenteeism and sick leave, death and funeral benefits, in-firm medical services, and the costs of recruiting and training replacement workers. Such direct costs for African firms are typically relatively low (Avetin and Huard (2000), McPherson et al (2000), Barnett and Whiteside (2002)). Part of the reason for this is the general lack of provision of pension and medical benefits to all workers. In South Africa's case, this is reinforced by the fact that HIV-positive workers appear to be concentrated in the lower skill bands ${ }^{19}$ which do not enjoy the same level of benefit provision as skilled and managerial employees.

The total impact on firms will vary depending on factors such as whether firms provide in-house medical facilities, the way in which employment benefits are structured, and the distribution of HIV-positive people across the skill-structure. ${ }^{20}$ Research in Kenya indicates that the cost of AIDS as a percentage of profits varied from 0.1 per cent in the case of heavy industry, to 7 per cent in the case of wood processing and transportation (Forsythe and Roberts, 1994).

Indirect or 'unquantifiable' costs include lower productivity of

18 See Avetin and Huard (2000) for a clear exposition of this methodology as applied to three manufacturing firms in Cote d'Ivoire, and Barnett and Whiteside (2002) for a summary of studies of this nature.

19 Byrne (2001:7) found in the cement plant which had undertaken the voluntary saliva seroprevalence test amongst its employees, that 79 per cent of HIV-positive individuals were in the lower (predominantly unskilled) job bands. Sanders (2001:16) reported that deaths in the Zimbabwe food manufacturing firm were all amongst the least skilled job categories. See also Morris et al (2000).

20 See ILO, 2000:13-18 for a discussion of the impact of AIDS on enterprises in Africa. The impact will also depend on how many HIV-positive workers remain in employment. For example, research on the impact of AIDS on a South African colliery found that many workers who test HIV-positive leave immediately because they 'cannot handle the news' and 'just get up and run away' (Kennedy, 2002:9). 
sick workers and the disruptive impact on teams and production processes. These are much harder to measure, but are potentially of great importance (Avetin and Huard, 2000; Barnett and Whiteside, 2002). For example, Kennedy in her study of the impact of AIDS on a South African coalmine, found that the impact was more discernable 'at the coal face' than it was in the eyes of senior management (2002).

Until recently, there were few reliable studies of the impact of AIDS on firms in South Africa. Press reports varied wildly and there was little clear understanding of how different estimates of productivity losses were arrived at (Michael, 2000; Abt Associates, 2000:40-1). Fortunately, research into the impact of AIDS on a sugar mill in KwaZulu Natal (Morris et al, 2000; Morris and Cheevers, 2000), and synthetic modelling work by Rosen et al (2000), are improving our understanding about the nature of the impact on firms in South Africa. ${ }^{21}$ However, this kind of empirical work remains (inevitably) subjective - both in terms of estimating indirect costs and in terms of how direct costs are framed and quantified - and difficult to generalize across the entire economy. Booysen and Molelekoa (2001) go some of the way towards rectifying this problem in their survey of firms in the Bloemfontein and Welkom areas. But while this study has the advantage of pooling the results from twenty firms, the results cannot be generalized to the region (only 10 per cent of surveyed firms responded, and most were small to medium-sized businesses) let alone to the whole of South Africa.

The standard demographic assumption in South Africa appears to be that individuals who contract HIV live for an additional seven to ten years and that most of the debilitating illness and symptoms are manifest in the last two years of life. The Natal sugar mill study found that in the two years prior to the men taking retirement (on grounds of ill-health), an average of 27.7 days were lost in each year (Morris et al, 2000:940). Of these, 11.7 days were accounted for by sickleave, 5.4 days by hospitalization,

21 See also Thea et als study of the impact of AIDS on 'Company A' (2000). 
and 10.6 by visits to the clinic (assuming that each visit to the clinic during work hours resulted in half a day lost).

Taking into account estimates for lost wages (due to lost days), the costs of hiring and training replacement workers (roughly doubled to proxy for lost productivity due to disruption) and limited clinic and hospital-related costs, they estimated the cost of each HIV infection to be roughly three times the annual salary in each of the final two years of employment. No adjustment was made for increased pension or medical aid costs, on the grounds that most (94 per cent) of the HIV-positive workers were in the lowest skill bands (Morris et al, 2000:939). These unskilled workers presumably did not have access to firmbased pension plans, and would have made use of government clinics rather than private medical facilities. ${ }^{22}$

In their modelling work on the impact of AIDS on South African firms, Rosen et al assume that direct firm-based medical expenditure is low. Instead, they focus on pension benefits, service gratuities and death benefits for HIV-positive workers, costs relating to sick leave and recruitment and training ${ }^{23}$ of replacement workers. These (present value of future) costs come to just under twice the annual salary of workers (see Table 3).

Rosen et al use the model to show how medical interventions that increase life expectancy save firms money (by pushing costs further into the future - thus causing them to be discounted more heavily). Their model shows that 'the present value of a new HIV infection would fall by 9 per cent if employees' average life expectancy could be extended for one year, by 25 per cent for a three year extension and by 38 per cent if five more years of productive life could be achieved' (ibid: 303 ). (These results simply

\footnotetext{
22 Morris and Cheevers (2000) report that the relatively low proportion of costs attributable to health care (11 per cent) is similar to that found in a study of six companies in Kenya (2000:7). They note that medical expenditure is not prominent in this population (i.e. the sugar mill) 'because of the public health system available' (2000:943).

23 They use data on recruitment and training from a five-firm study in Botswana.
} 
reflect the fact that a 10 per cent discount rate is being applied). The implication is that any treatment costing less than R4,412 that extends productive life by a year would be feasible for those on salaries of R25,000 or lower. For higher-paid (skilled) workers, the upper limit of economically feasible treatment rises to R8,433 and R16,475.

Table 3. Rosen et al's Present V alue of the Future Costs of a New HIV Infection, assuming a Seven Year Interval between Infection and Death

\begin{tabular}{llll}
\hline Cost component (2000) & Salary = R25,000 & Salary = R50,000 & Salary = R100,000 \\
Paid sick leave & R5,741 & R11,481 & R22,961 \\
Pension benefits & $\mathrm{R} 38,487$ & $\mathrm{R} 76,974$ & $\mathrm{R} 15,947$ \\
Recruitment / training & $\mathrm{R} 4,313$ & $\mathrm{R} 4,313$ & $\mathrm{R} 4,313$ \\
Total & $\mathbf{R} 48,540$ & $\mathbf{R} 92,767$ & $\mathbf{R} 181,222$ \\
Ratio of total costs to annual salary & 1.94 & 1.86 & 1.81 \\
Savings (life extended by one year)* & $\mathrm{R} 4,412(9 \%)$ & $\mathrm{R} 8,433 \quad(9 \%)$ & $\mathrm{R} 16,475 \quad(9 \%)$ \\
Savings (life extended by three years)* & $\mathrm{R} 12,071(12 \%)$ & $\mathrm{R} 23,070(12 \%)$ & $\mathrm{R} 45,067(12 \%)$ \\
Savings (life extended by five years)* & $\mathrm{R} 18,400(38 \%)$ & $\mathrm{R} 35,166(38 \%)$ & $\mathrm{R} 68,697(38 \%)$ \\
\hline
\end{tabular}

* Savings are reductions in the present value of future costs of a new HIV infection due to interventions that extend life by one, three or five years. A discount rate of 10 per cent is used. The figures in parentheses are total savings as a percentage of base-line costs.

Source: Rosen et al (2000).

Booysen and Molelekoa (2001) adopt a similar methodology to estimate the impact of AIDS on the twenty firms they surveyed in Bloemfontein and Welkom. Their figures were similar to those reported in Rosen et al (see Table 3). Booysen and Molelekoa's estimated present value of the cost per AIDS death was R44,319 for unskilled employees, R70,437 for skilled employees, and R190,877 for highly-skilled employees (2001:15). However, the ratio of total costs to annual salary was more sensitive to skills level in the Booysen and Molelekoa study (1.35 for unskilled, 1.27 for skilled and 2.5 for the highly-skilled). This appears to be because the information obtained from the survey allowed them to differentiate more clearly than Rosen et al between the different benefits provided for different skill levels. They found that only a quarter of firms offered medical benefits (and in those cases, mostly to skilled workers (2001:9)). Booysen and Molelekoa conclude that the average savings to firms of extending productive 
life by one year is R5,491 per worker (20001:16).

Note that the estimates discussed so far only take direct costs into account. Once indirect costs and benefits are factored into the calculation, then the case for life-saving interventions becomes even more compelling for firms. As Rosen et al explain:

'The financial benefits of pushing further into the future the types of costs analyzed above are only a subset of the overall gains to a company of investing in keeping its workforce as healthy as possible for as long as possible. By retaining skilled and experienced employees for an additional year or years, the company also:

* buys time for drug prices to fall and for medical and social science researchers to develop new ways to treat HIV/AIDS;

* reduces the time managers must spend coping with employee deaths and high turnover;

* reduces the impact on the morale, motivation and concentration of the rest of its workforce of having colleagues fall sick and die; and

*creates more time to implement strategies to cope with the epidemic, such as training replacement employees, shifting to less intensive-intensive technologies, and managing the loss of overall workforce skill, experience, institutional memory and cohesion that HIV/AIDS is causing.' (2000:303).

When Rosen et al did their study, the cost of antiretroviral medication for a worker (i.e. over R36,000 a year) was between two and nine times higher than the (direct) benefits to business of providing such medication. However, as of mid-2001, the cost of antiretroviral medication had fallen so much, that Medicare (a medical aid company in South Africa) was able to provide antiretroviral medication and CD4 counts and blood tests for about R800 a month - i.e. about R9,600 a year (Regensberg, 2001). If we assume the firm absorbs half these costs, then this will amount to $\mathrm{R} 4,800$ a year. Assuming a discount rate of 10 per cent, the present value of projected expenditure on antiretrovirals over three years is R13,131 and over five years it is R20,016. As indicated by the data in Table 4, this suggests that it will be cost-effective for firms to provide access to antiretroviral medication to their more highly skilled personnel and that the cost (to the company) is only marginally higher than the benefits of extending the lives of less skilled workers for a year. However, as discussed above, 
these results consider only the direct costs of AIDS. Once indirect costs are included, the cost-effectiveness of providing antiretroviral medication to workers becomes much more compelling.

Table 4. Net Savings to Firms as a Result of Providing Antiretroviral Treatment to Workers (own calculations)

\begin{tabular}{|c|c|c|c|}
\hline & Additional 1 year & Additional 3 years & Additional 5 years \\
\hline $\begin{array}{l}\text { Discounted cost to firms of } \\
\text { ARV treatment }\end{array}$ & $\mathrm{R} 4,800$ & $\mathrm{R} 13,131$ & $\mathrm{R} 20,016$ \\
\hline $\begin{array}{l}\text { Net savings (for salaries of } \\
\text { R25,000) }\end{array}$ & $\begin{array}{l}\mathrm{R} 4,412-\mathrm{R} 4,800=- \\
\mathrm{R} 388 \\
(\mathrm{R} 4,024)\end{array}$ & $\begin{array}{l}\mathrm{R} 12,071-\mathrm{R} 13,131 \\
=-\mathrm{R} 1,060 \\
(\mathrm{R} 11,011)\end{array}$ & $\begin{array}{l}\mathrm{R} 18,400-\mathrm{R} 20,016 \\
=-\mathrm{R} 1,616 \\
(\mathrm{R} 16,784)\end{array}$ \\
\hline $\begin{array}{l}\text { Net savings (for salaries of } \\
\text { R50,000) }\end{array}$ & $\begin{array}{l}\mathrm{R} 8,433-\mathrm{R} 4,800= \\
\mathrm{R} 3,633 \\
(\mathrm{R} 12,066)\end{array}$ & $\begin{array}{l}\text { R23,070-R13,131 } \\
=\text { R9,939 } \\
\text { (R33,009) }\end{array}$ & $\begin{array}{l}\text { R35,166-R20,016 } \\
=\mathrm{R} 15,150 \\
(\mathrm{R} 50,316)\end{array}$ \\
\hline $\begin{array}{l}\text { Net savings (for salaries of } \\
\text { R100,000) }\end{array}$ & $\begin{array}{l}\mathrm{R} 16,475-\mathrm{R} 4,800= \\
\mathrm{R} 11,675 \\
(\mathrm{R} 28,150)\end{array}$ & $\begin{array}{l}\text { R45,067-R13,131 } \\
=\text { R31,936 } \\
(\mathrm{R} 77,003)\end{array}$ & $\begin{array}{l}\text { R68,697-R20,016 } \\
=\mathrm{R} 48,681 \\
(\mathrm{R} 117,378)\end{array}$ \\
\hline
\end{tabular}

Sources: Calculated from data in Rosen et al (2000), see Table 3, and Regenberg (2001) assuming a discount rate of 10 per cent. The figures in parentheses include an estimate for productivity losses (i.e. indirect costs) which doubles the savings shown in Table 3.

If, following the KwaZulu sugar mill study, we assume that the indirect cost of AIDS (i.e. on productivity, team-cohesion etc.) amounts to about 50 per cent of total (direct and indirect) economic costs, then we can double the Rosen et al estimates to include these factors. ${ }^{24}$ This will push the Rosen $e$ al estimate for the lowest-paid workers up to R97,080 and make it feasible to provide antiretrovirals even to the low-skilled workers. As can be seen from the figures in parentheses in Table 4, doubling the economic costs (as a rough proxy for including indirect costs) renders it economically feasible for firms to treat all workers with antiretrovirals in order to prolong life and minimize disruption.

This kind of exercise illustrates the important point not yet taken into account by macroeconomic modellers - i.e. that firms can react to minimize the impact of AIDS on their businesses. As argued above, firms may chose to provide antiretrovirals to their skilled workers - and perhaps even to all workers - thereby

\footnotetext{
24 This is consistent with research from East Africa showing high costs associated with disruption of production (ILO, 2000:14).
} 
extending the life of the workforce and minimizing the disruptive impact on the labour market and patterns of consumption. All three macroeconomic models discussed above assumed that providing antiretroviral medication was out of the question. While this is understandable with regard to the ING-Barings and Arndt and Lewis studies (because the cost of antiretrovirals was still high in 2000), it is less understandable with respect to the BER study (as the costs of antiretrovirals had fallen dramatically before the study was published). If firms do react by providing antiretrovirals (as is already the case with Anglo-American and Mondi) then all three macroeconomic models will have overestimated the impact of AIDS on the workforce, skills shortages, wages, consumption and medical costs. They would, in other words, have over-estimated the impact of AIDS on growth and per capita incomes.

Another way for firms to respond to the AIDS pandemic, is to reduce their exposure to the risks and costs associated with AIDS. According to Rosen and Simon (2002), there is an emerging body of evidence that firms in Sub-Saharan Africa are avoiding some of the burdens of AIDS through reducing employee benefits, restructuring employment contracts, outsourcing less skilled jobs, selective retrenchments and changes in production technologies. All of these changes have implications for the rate and pattern of economic growth. While some of the changes help lower the cost of AIDS to individual firms (by shifting the burden of AIDS from firms to the public sector, workers' families and society at large), the private sector as a whole will still feel the effects - albeit via different routes. As McPerson et al point out, "as the HIV/AIDS epidemic intensifies, the macroeconomic effects of these rising costs will feedback to affect the employers' output, sales, taxes, or access to social services" (2000:8). In other words, some direct costs can be passed on to others, but the overall macroeconomic impact cannot be avoided. This is because AIDS affects firms through various channels including the demand for their output, efficiency losses on the production side and via changes in the social and legal environment (see Naidoo, 2001; Barnett and 
Whiteside, 2002).

In addition to reacting to the risks associated with HIV infection in their workforce, firms will also react to AIDS-related changes in the demand for their products. In a recent publication by J.P. Morgan (2001) entitled 'How to AIDS-Proof Your Consumer Portfolio', investors are advised to avoid companies whose consumers are relatively young and relatively poor - or whose products are luxury goods with a high income-elasticity of demand (because these companies could suffer as expenditure is reallocated towards health spending) or who rely on consumer purchases on credit (as defaults are likely to become more common $^{25}$ ). This kind of market advice is likely to depress stock prices for such firms and industries - thus sending a signal to entrepreneurs to diversify and gradually shift out of such markets. The JD group (which sells furniture and household appliances) has already concluded that its target South African market is likely to be adversely affected by AIDS, and as a consequence has opened stores in the Czech Republic and Poland in order to protect its rate of return to shareholders (Whiteside and Sunter, 2000:106-107).

\section{CONCLUSION}

What does the discussion so far suggest about the impact of AIDS on distribution in South Africa? The data and information is sketchy and uneven, and macroeconomic and firm-level modelling work is highly dependent on theoretical and other assumptions. Nevertheless, some worrying themes suggest themselves. If firms react by continuing to decrease their reliance on unskilled labour (a trend that started before the AIDS pandemic) and by moving out of economic sectors whose customer-base comprises lower-

25 MetAM is reported in the Business Day, 17 Jan 2002 as follows: "People will have less disposable income due to rising medical and insurance costs. Consumers will pose an increased credit risk to retailers. With credit retailers expected to be more affected, our retail stock picking has been favouring those companies that target the upper section of the market where credit risk is lower". 
income consumers, then poor households will find themselves doubly disadvantaged. Not only will their access to the labour market become ever more tenuous, but the products that they purchase may become scarcer (and more costly).

Conversely, relatively skilled workers could benefit from greater employment opportunities (as production becomes more skill- and capital-intensive) and higher wages (as the relative demand for skilled labour increases). They will probably also live longer and more productive lives as firms begin to provide them with greater access to antiretroviral medication. The size of the pie may shrink as a result of AIDS, but employed (especially skilled) workers will enjoy a growing share.

South Africa is increasingly divided along class lines with the gap between the employed and unemployed being of major importance (Nattrass and Seekings, 2001). The horrifying element that AIDS brings to the picture is that the divide will mean the difference between life and death for many people. Those without access to jobs (especially good jobs) will bear the brunt of the AIDS pandemic. Whether inequality is lower or higher twenty years from now is a moot point. But over the next couple of decades, inequality will probably rise as AIDS lowers growth and increases the burden borne by the poor.

\section{REFERENCES}

ABT AssociATES. (2000). HIV/ AIDS in South Africa - Implications for Investors, Report prepared for J.P. Morgan.

AbT/Metropolitan. (2000). Demographic Impacts of HIV/AIDS in South Africa. A study prepared for the Department of Finance by Abt Associates and Metropolitan AIDS Research Unit, June.

AinsworTh, M. AND M. Over. (1994). "AIDS and African Development", in World Bank Research Observer, vol.9, no.2.

ARNDT, C. AND LEWIS, J. (2000). "The Macro Implications of HIV/AIDS in South Africa: A Preliminary Assessment", South African Journal of Economics, August 2000.

Avetin, L. And Huard, P. (2000). "The Cost of AIDS to Three Manufacturing Firms in Cote d'Ivoire, in Journal of African Economies, vol.9, no.2.

BARnetT, T. AND A. WhiteSIDE. (2002). AIDS in the Twenty-First Century, Palgrave Macmillan, New York.

BonNel, R. (2000). "HIV/AIDS and Economic Growth: A Global Perspective", in The South African Journal of Economics, vol.65, no.5.

BoOysen, F. AND J. MOLELEKOA. (2001a). "The Benefit to Business of Extending the Working Lives of HIV-positive Employees: Evidence from Case Studies in Bloemfontein and 
Welkom, Free State Province". Paper presented at the International AIDS in Context Conference, 4-7 April, University of the Witwatersrand, Johannesburg, South Africa.

Booysen, F., VAn Rensburg, R., BaChmann, M., O’Brien, M. And F. STEyn. (2001)b. “The Socio-Economic Impact of HIV/AIDS on Households in South Africa: Pilot Study in Welkom and QwaQwa, Free State Province, Draft Interim Report, Centre for Health Systems Research and Development, University of the Free State.

Booysen, F. (2002)b. "Financial responses of households in the Free State Province to HIV /AIDS-related morbidity and mortality", in South African Journal of Economics, vol. 70, no.7.

Broomberg, J., Steinberg, M., Moasobe, P. And G. BeHr. (1991). "The Economic Impact of the AIDS Pandemic in South Africa", in Centre for Health Policy, AIDS in South Africa. The Demographic and Economic Implications, University of the Witwatersrand, Johannesburg.

BER. (2001). "The Macro-Economic Impact of HIV/AIDS in South Africa", Bureau for Economic Research, University of Stellenbosch, Paper no.10, September 7. Compiled by Smit, B., Visagie, L. and P. Laubscher.

BloOm, D. AND A. MAHAL. (1997). "Does the AIDS Epidemic Threaten Economic Growth", in Journal of Econometrics, vol.77.

Byrne, H. (2001). "Reacting to the Threat of AIDS: An Exploratory Case Study of a South African Firm", Honours Long Paper, School of Economics, University of Cape Town. Research supported by the Anglo-American Chairman's Fund.

CADRE. (2000a). The Economic Impact of HIV/ AIDS on South Africa and its Implications for Governance: A Bibliographic Review, November 2000, CADRE, Johannesburg.

CADRE. (2000b). The Economic Impact of HIV/ AIDS on South Africa and its Implications for Governance: A Literature Review, CADRE, Johannesburg.

DIKE, S. (2002). "Research on the Economic Impact of HIV/AIDS in South Africa: Review of Methodology and Lessons Learned", in the South African Journal of Economics, vol.70, no.7.

Dorrington, R. (2001). "The Demographic Impact of HIV/AIDS in South Africa by Province, Race and Class", Centre for Actuarial Research, University of Cape Town.

FEDDERKE, J. AND M. MARIOTTI. (2002). "Changing labour market conditions in South Africa: A sectoral analysis of the period: 1970-97”, in The South African Journal of Economics, vol.70, no.5.

FORSYTHE, S. AND M. ROBERTS. (1994). "Measuring the impact of HIV/AIDS in Africa's Commercial Sector: A Kenyan Case Study", in AIDS Analysis Africa, vol.4, no.5.

ILO. (2000). HIV/ AIDS in Africa: The Impact on the World of Work, International Labour Office, Geneva.

ING-Barings. (2000). Economic Impact of AIDS in South Africa: A Dark Cloud on the Horizon, Report by Kristina Quatteck, ING-Barings Global Research.

JPMorgan. (2001). "How to AIDS-Proof your Consumer Portfolio", Fleming Martin Securities, Johannesburg.

KenNEDy, C. (2002). "From the Coal Face: A Study of the Response of a South African Colliery to the Threat of AIDS", Centre for Social Science Research Working Paper no.5, University of Cape Town. Available on www.uct.ac.za/depts/cssr/pubs.html

McPherson, M., HoOver, D. AND D. SNOdgrass. (2000). "The Impact on Economic Growth in Africa of Rising Costs and Labor Productivity Losses Associated with HIV/AIDS",

CAER II Discussion Paper no.79, Harvard Institute for International Development, Cambridge.

Michael, K. (2000). "Unbelievable: AIDS Reporting in the Business Press", in AIDS Analysis Africa, vol.10, no.4. Dec 1999/ Jan 2000.

Morris, C., Burdge, D. AND E. CheEvers. (2000). "Economic Impact of HIV Infection in a Cohort of Male Sugar Mill Workers in South Africa", in South African Joumal of Economics, vol.68, no. 5 .

AND E. CheEvers. (2000). "The Direct Costs of HIV/AIDS in a South African Sugar Mill”, in AIDS Analysis Africa, vol.10, no.5, Feb/March.

NAIDOO, V. (2001). "The Impact of HIV/AIDS on the Macro Market Environment, CSSR

Working Paper no.3, AIDS and Society Research Unit, Centre for Social Science Research, University of Cape Town.

NAtTrass, N. (2000). "The Debate about Unemployment in the 1990s", in Studies in Economics and 
Econometrics, vol.24, no.3.

and J. SEekiNGs. (2001). "Two Nations: Race and Economic Inequality in South African Today" in Daedalus, Spring 2001.

Oni, S., OBI, C., OKOrie, A., ThaBede, D., JordaAn, A. (2002). "The Economic Impact of HIV/AIDS on Rural Households in Limpopo Province", in South African Journal of Economics, vol.70, no.7.

Over, M. (1992). "The Macroeconomic Impacts of AIDS in Sub-Saharan Africa. World Bank, Technical Paper no.3., Washington, D.C.

Regensberg, L. (2001). “Aid for AIDS: A Disease Management Programme for HIV/AIDS”, Presentation to the Actuarial Science Seminar, University of Cape Town, May.

Rosen, S., Simon, J. And J. VinCENT. (2000). "Care and Treatment to Extend the Working Lives of HIV-positive Employees: Calculating the Benefits to Business", in South African Journal of Science, no.96, June: 300-305. . and __. (2002). "Shifting the Burden of HIV/AIDS, Centre for International Health, Boston University, Boston USA.

SAMSON, M. (2002). "HIV/AIDS and Poverty in Households with Children Suffering from Malnutrition: The Role of Social Security in Mount Frere", in South African Journal of Economics, vol.70, no.7.

SANDERS, C. (2001). "The Economic Impact of HIV/AIDS on a Zimbabwean Food Manufacturing Firms", Honours Long Paper, School of Economics, University of Cape Town. Research supported by the Anglo-American Chairman's Fund.

SEekings, J. (2000). "Visions of Society: Peasants, Workers and the Unemployed in a Changing South Africa", in Studies in Economics and Econometrics, vol.24, no.3.

ShisAnA, O. AND L. SimBAYI. (2002). South African National HIV Prevalence, Behavioural Risks and Mass Media, Nelson Mandela/HSRC Study of HIV/AIDS, HSRC, 2002.

SteinberG, J., Johnson, S., SChierhout, G. AND D. NDEGWA. (2002)b. Hitting Home: how Households Cope with the Impact of the HIV/AIDS Epidemic: A Survey of Households Affected by HIV/AIDS in South Africa Kaiser Family Foundation and the Health Systems Trust.

Thea, D., Rosen, S., Vincent, J., Singh, G. And Simon, J. (2000). "Economic Impact of HIV/AIDS in Company A's Workforce", International AIDS Conference, Durban.

Trotter, G. (1993). "Some Reflections on the Human Capital Approach to the Analysis of the Impact of AIDS on the South African Economy", in Cross, S. and A. Whiteside, Facing up to AIDS: The Socio-Economic Impact in Southern Africa, Macmillan, London.

Whiteside, A. AND C. SunTER. (2000). AIDS: The Challenge for South Africa, Human and Rousseau, Cape Town. 